INDEPENDENT JOURNAL OF MANAGEMENT \& PRODUCTION (IJM\&P)

\title{
BUSINESS PROCESS MODELING: A WEBIBLIOMINIG PERSPECTIVE OF ARCHITECTURE FRAMEWORKS
}

\author{
Gabriel Riso Oliveira \\ Universidade Estadual do Norte Fluminense (UENF) \\ Campos dos Goytacazes - RJ, Brasil \\ E-mail: gabriel.riso@gmail.com
}

Ailton da Silva Ferreira Universidade Federal Fluminense (UFF)

Rio das Ostras - RJ, Brasil

E-mail: ailtonsilvaferreira@yahoo.com.br

Submission: 07/09/2016

Revision: 23/09/2016

Accept: 08/06/2017

\section{ABSTRACT}

In the perspective of organizational context, the present paper deals with the different types of architecture of BPM. As objectives, it is proposed to formulate a conceptual model of the main architectures present in the scientific literature based on methodological and logical webibliomining. As for the methodology, it is utilized Web of Science database and the software Nails in order to promote the logical pathway of the proposed webibliomining research. Both quantitative and qualitative analysis are part of the approach to the subject. As a result, the conceptual view of the UML, BPMN, CIMOSA, IDEF, ARIS, IEM, GRAI, GERAM and EKD architectures is developed, in terms of temporal aspects, socio-technical characteristics, visualization and analysis, among other factors which offers substantial argument to decide what framework is better in each scenario.

Keywords: Business Process Modeling; Organizational Modeling; Modeling;Webibliominig; Architecture Framework 


\section{INTRODUCTION}

In the nowadays industrialized world, the organizational processes, or still business processes, have become extremely relevant tools for the management of modern organizations, which are inserted in a competitive market with increasingly demanding clients.

In this context, identifying and assimilating the workflow of organizational environments is a necessary condition for the development of processes improvement, which, in turn, generate benefits such as efficiency gains, quality and flexibility; as well as other aspects conducive to sustainable competitive advantages.

In the definition of Conforti, Dumas, García-Bañuelos and Rosa (2016), a process encompasses elements of work (action) and resources (people, equipment, information) in order to achieve a result for a specific consumer.

In this context, business process modeling is the practice of science to verify how this work and resources are arranged in an organization to identify opportunities for improvement and, consequently, positive results. This resource disposition refers to the way in which modeling is organized, that is, its architecture.

There is a large number of researches in the scientific literature on business process modeling architectures. In the view of Rosa, Van Der Aalst, Dumas and Milani (2017), this theme has become a mature discipline, exhibiting a well-defined set principles, methods and tools that combine knowledge of information technology, management sciences and industrial engineering with the aim of continuously improving business processes.

Exploring the concepts, we can identify several methodologies and architectures that characterize the different applications of the process modeling theme such as: BPMN (Business Process Model and Notation); UML (Unified Modeling Language); ARIS (Architecture of Integrated Information Systems); CIMOSA (Computer Integrated Manufacturing Open System Architecture); IDEF (Integration DEFinition); among others. Such a variety engenders an aspect of complexity in choice by a method that is efficient to promote the goal of process improvement in organizations. 
INDEPENDENT JOURNAL OF MANAGEMENT \& PRODUCTION (IJM\&P)

http://www.ijmp.jor.br

v. 10, n. 3, May - June 2019

ISSN: 2236-269X

DOI: 10.14807/ijmp.v10i3.886

The main objective of this paper is to propose a comparative and conceptual analysis promoted by a logical webiblioming research; which provides an accurate and rational overview of the state of the art of literature regarding the main reference architectures of BPM in the scientific environment. In this context, this paper seeks a better understanding of the main modelling methodologies in academic field about organizational processes and organizational management environment.

In addition to the webibliomining data, the systematic quantitative and qualitative approach of scientific research and recent empirical studies of relevant authors of literature is based on the proposal of a conceptual comparative analysis adapted from the work developed by the authors Barat, Kulkarni, Clark and Barn (2016).

Therefore, this paper is organized as follows: Section 2 provides the Theoretical Framework that serves as an elementary basis for sustaining the development of the theme throughout the article; In section 3, the Methodological Resources are presented with the intention of conferring scientific ballast and listing the stages of the research in a coherent way; Section 4 encompasses the Webibliomining Analysis performed on the subject of modeling architectures. Section 5 presents the duly grounded Conclusion of the topic discussed; Finally, the bibliographic references are presented at the end of the paper.

\section{BACKGROUND}

The theoretical reference of the present paper is centered in ascertaining the main aspects and characteristics of the architectures of modeling of business processes more common to the scientific literature, obtained with the aid of extensive systematized bibliographical research. In this context, the modeling techniques will be emphasized: BPMN; UML; ARIS; CIMOSA; and IDEF.

As secondary approaches, due to the lower popularity in the literature, the following sub-topic entitled "Other business process modeling architectures" is briefly discussed in the following methodologies: IEM (Integrated Enterprise Modeling); GERAM (Generalised Enterprise Reference Architecture and Methodology); EKD (Enterprise Knowledge Development); e GRAI (Graphs with Results and Actions Inter-related). 
INDEPENDENT JOURNAL OF MANAGEMENT \& PRODUCTION (IJM\&P)

http://www.ijmp.jor.br

v. 10, n. 3, May - June 2019

ISSN: 2236-269X

DOI: 10.14807/ijmp.v10i3.886

\subsection{BPMN}

BPMN is considered a highly efficient generic modeling architecture for modeling business processes across multiple domains of interest, relying on a considerable amount of tools and techniques that facilitate process management activities. As for its symbology, or flow architecture, we have the elements: start event; end event; c) task; gateways, decision structures; and flow arrow of the model. An example of the application of this symbology is given in figure 01 .

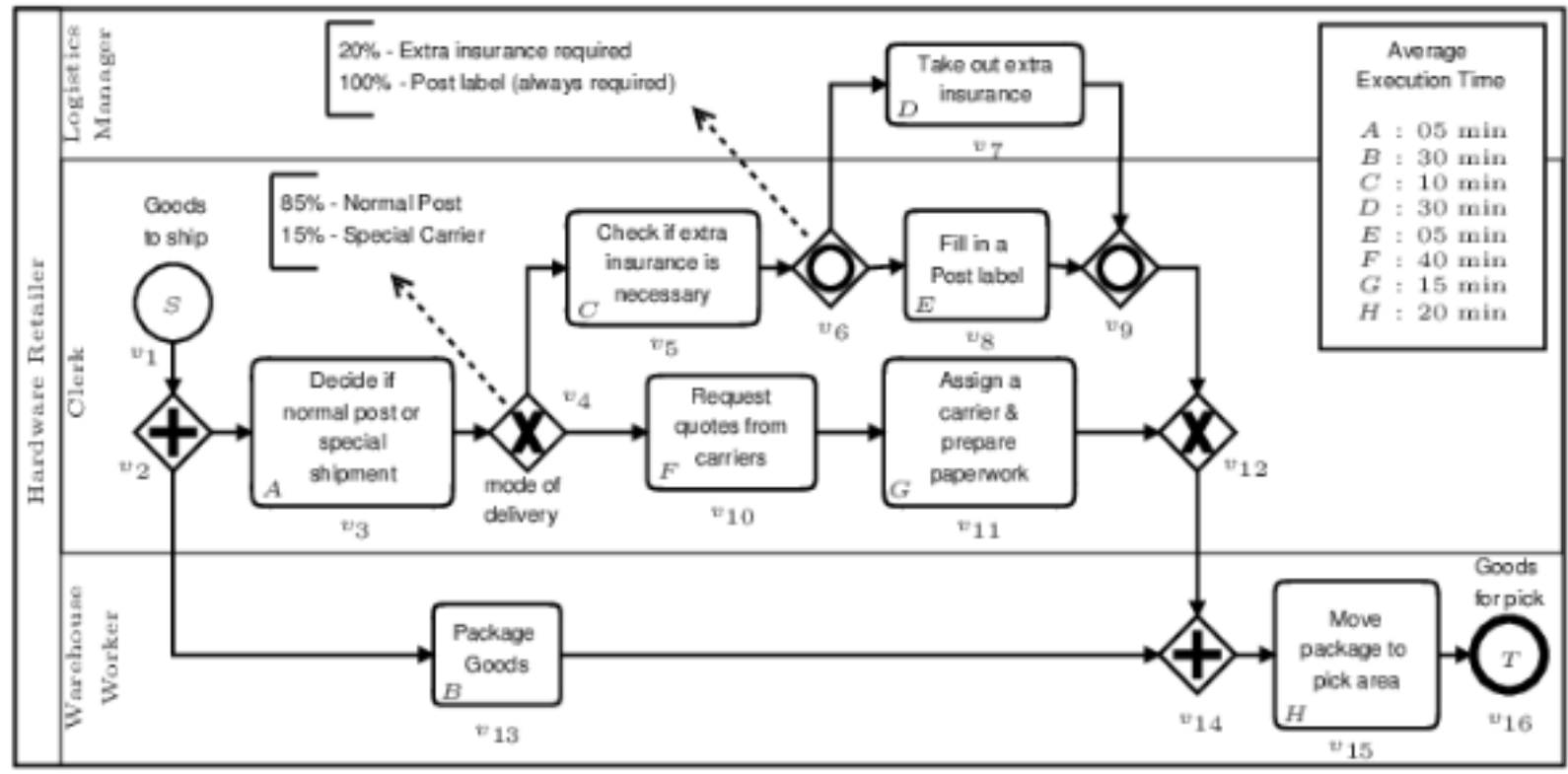

Figure 1: Example of BPMN

Source: Braghetto, Ferreira and Vincent (2011)

In the study promoted by Yan et al. (2018) about the compliance levels of procedures used for the redesign of clinical processes, one can verify the flexible semantics of the BPMN architecture, which facilitates the analysis of complex protocols. In this same work, the flexibility aspect of BPMN is also exalted when adapting matrices of time $X$ tasks (very commonly used in the clinical sector) to a BPMN model of heuristic characteristic.

Another proof of BPMN's flexibility in its application to different domains of interest is set forth in the research by Chinosi and Trombetta (2012), which affirms BPMN as the standard to graphically represent processes that occur in virtually all types ranging from cooking recipes to the Nobel Prize-awarding process, incident management, e-mail voting systems, travel booking procedures, and more.

Mendling, Recker, Reijers, and Leopold (2018) explain that BPMN covers the areas of process documentation and scenario improvement (process optimization) 
INDEPENDENT JOURNAL OF MANAGEMENT \& PRODUCTION (IJM\&P)

http://www.ijmp.jor.br

v. 10, n. 3, May - June 2019

ISSN: 2236-269X

DOI: 10.14807/ijmp.v10i3.886

using technical process modeling applications such as workflow engineering, simulation, or service composition web. Such techniques consist of a core of major graphics and a set of additional "configurations".

Since the same authors define that the graphic set is sufficient to describe the essence of business processes, since it aims to generate intuitive models; While the additional set provides constructs to support advanced process modeling concepts (which require more detail by their complexity), such as orchestration and process choreography, workflow specification, event-based decision making, and exception handling .

Haisjackl, Soffer, and Lime Weber (2018) have shown that individuals are more likely to use the overview strategy to understand and assimilate BPMN models, thus confirming the fact of efficient graphical representation in this modeling technique, once that the data and the relationships between data are presented in an agile way, one can have a quick view of the whole system.

Thus, in the BPMN architecture, processes are modeled by information flows. This is due to the fact that a flow of information transits between departments and is controlled by different stakeholders involved in the company, rather than being tied to a specific system.

Therefore, the flexible and dynamic nature of the BPMN models applied to the real processes and their clear relation with the concept of "horizontalization" in matrix management in a company, or simply, process management, is perceived.

\subsection{UML}

In a brief introductory definition of UML, Fowler (2014) explains the modeling technique as being a set of graphical notations, supported by a base that helps in the description of the domain of interest and in the design of software systems, those that are built using the object-oriented style; Larman (2002) can be defined as a diagram notation used to specify, construct, and document the artifacts of systems.

The authors Karim, Liawatimena, Trisetyarso, Abbas and Suparta (2017) support the concept that the UML architecture is based on structural, behavioral and interaction elements that provide a standard notation for the preparation of architecture plans for systems projects information, including conceptual aspects such as business processes and system functions. 
INDEPENDENT JOURNAL OF MANAGEMENT \& PRODUCTION (IJM\&P)

http://www.ijmp.jor.br

v. 10, n. 3, May - June 2019

ISSN: 2236-269X

DOI: 10.14807/ijmp.v10i3.886

According to its creators Booch, Rumbaugh and Jacobson (2006), there was a clear purpose to encourage the standardization of language to aid in the development and modeling of software project structures through UML diagrams.

Ambler (2004) and Larman (2002) establish the class diagram as the most relevant diagram to represent a system model. The classes (components of the system), their attributes (characteristics) and their methods (actions) are described in Cosio et al (2018) research about the development of Pervasive Healthcare Systems, which consists on approaching monitoring solutions into the hands of the patients. The relations of interaction between objects in the class diagram in those systems are represented in figure 02.

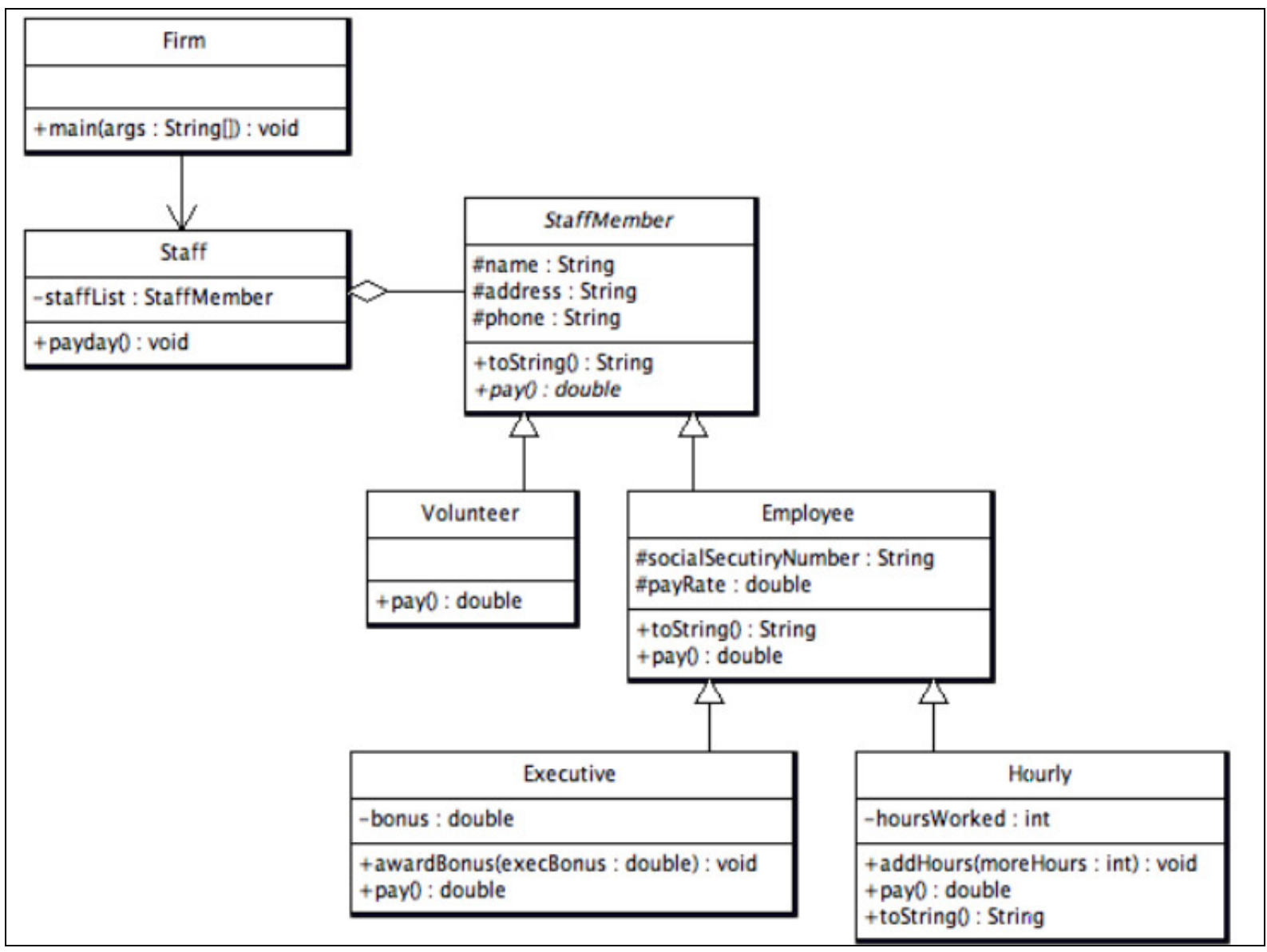

Figure 2: UML Class Diagram

Source: Cosío et al. (2018)

Pessini, Santander, Silva, Andrade and Schemberger (2017), explaining the aspects of agility and simplicity in modeling, explain that the methodology used in UML logic and its visual resources make discussions at a strategic organizational level about a given project more efficient in which information has to be debated and adapted to the guidelines given by different professionals with different degrees of 
intelligence in software and systems programming. Figure 3 shows a diagram of UML use cases.

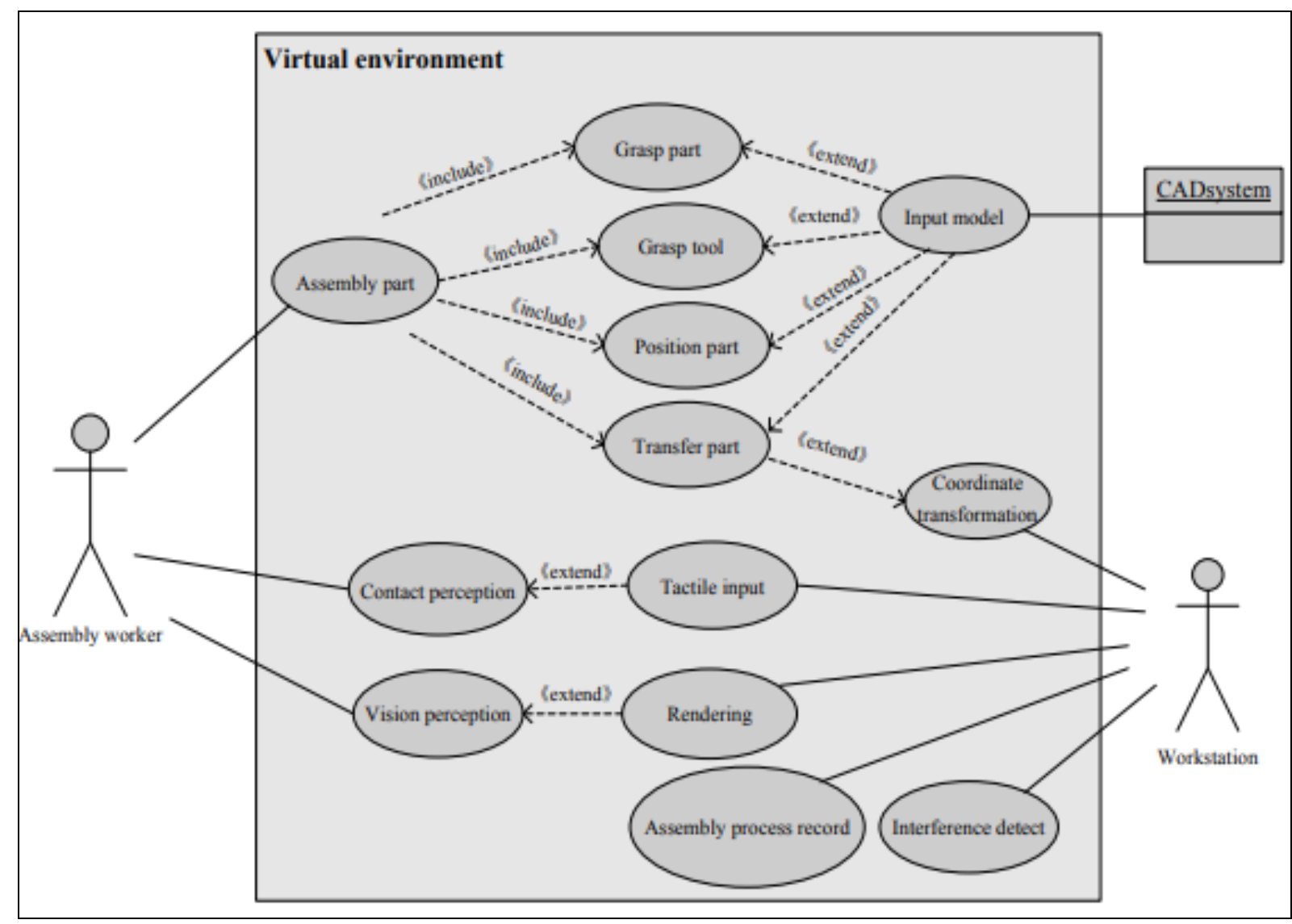

Figure 3: UML Use Case Diagram

Source: Yu, Gu, Liu, Sun, Qian and Guo (2017)

\subsection{ARIS}

The Event Driven Process Chain (EPC), a simplified part of the ARIS methodology, displays flowcharts developed to model business processes that are easily understood and used, their basic elements being data, process and functions, as shown in the schematic representation of Figure 04.

Panayiotou, Stavrou and Gayialis (2017), in their work of applying the ARIS architecture to design supply chain processes in small and medium enterprises, affirm that this technique of process modeling originated from as a proposal for simplification in the face of increasing complexity in process modeling of business, due to the increase in the number of business process modeling methods available.

The same authors also highlight the different perspectives that can be applied to the ARIS architecture, which in the specific case study covered different views of the supply chain as: processes and activities, organization, information systems, risk 
INDEPENDENT JOURNAL OF MANAGEMENT \& PRODUCTION (IJM\&P)

http://www.ijmp.jor.br

v. 10, n. 3, May - June 2019

ISSN: 2236-269X

DOI: 10.14807/ijmp.v10i3.886

management and decision making. Therefore, the dynamism aspect is assumed as inherent to this modeling technique.

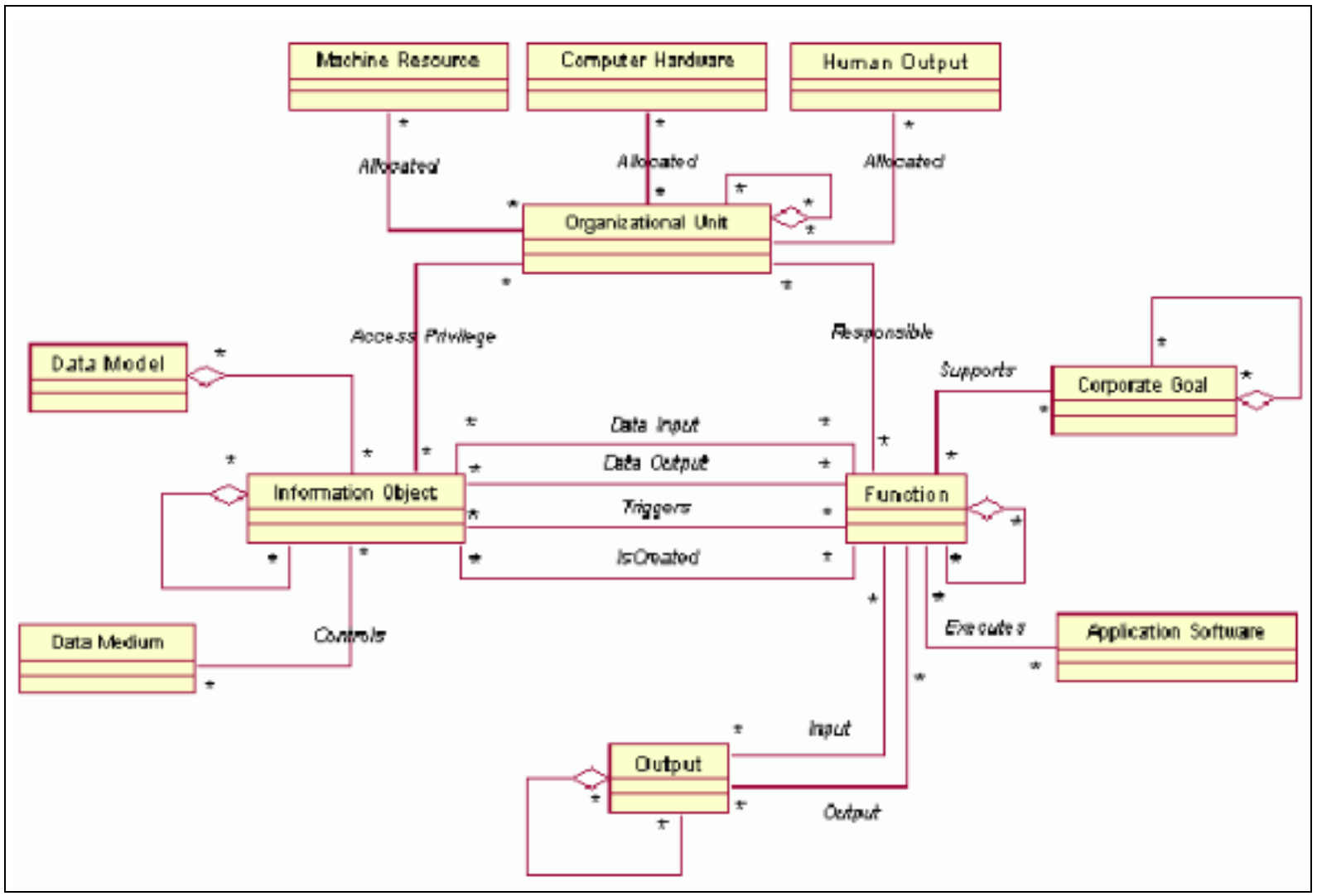

Figure 4: ARIS Architecture Framework

Source: Tbaishat (2017)

Rosa et al. (2017) explain that the architecture used by ARIS explains the flow of control of a process in terms of logical and temporal dependence of activities and this makes its graphical modeling intuitive. Such language is focused on the capture and understanding of processes for scope of projects and to discuss business requirements and process improvement initiatives with specialists in the domains of interest.

\subsection{CIMOSA}

The authors Latiffianti, Siswanto, Wiratno and Saputra (2017), who promoted a business process mapping with CIMOSA in companies with the objective of effective management of their value chains, explain that this modeling technique was initially designed for companies based in the Computer Manufacturing Integrated (CIM) system but is also suitable for other types of manufacturing systems (as proven in its case study). 
INDEPENDENT JOURNAL OF MANAGEMENT \& PRODUCTION (IJM\&P)

http://www.ijmp.jor.br

v. 10, n. 3, May - June 2019

ISSN: 2236-269X

DOI: 10.14807/ijmp.v10i3.886

The same authors divide the CIMOSA architecture into two parts: a particular architecture, which is defined as a set of models documenting the business environment; and a reference architecture used to assist users in the process of constructing their own particular architecture with a set of models describing the various aspects of the company at different levels of modeling. The general aspects of the CIMOSA architecture can be checked in figure 05.

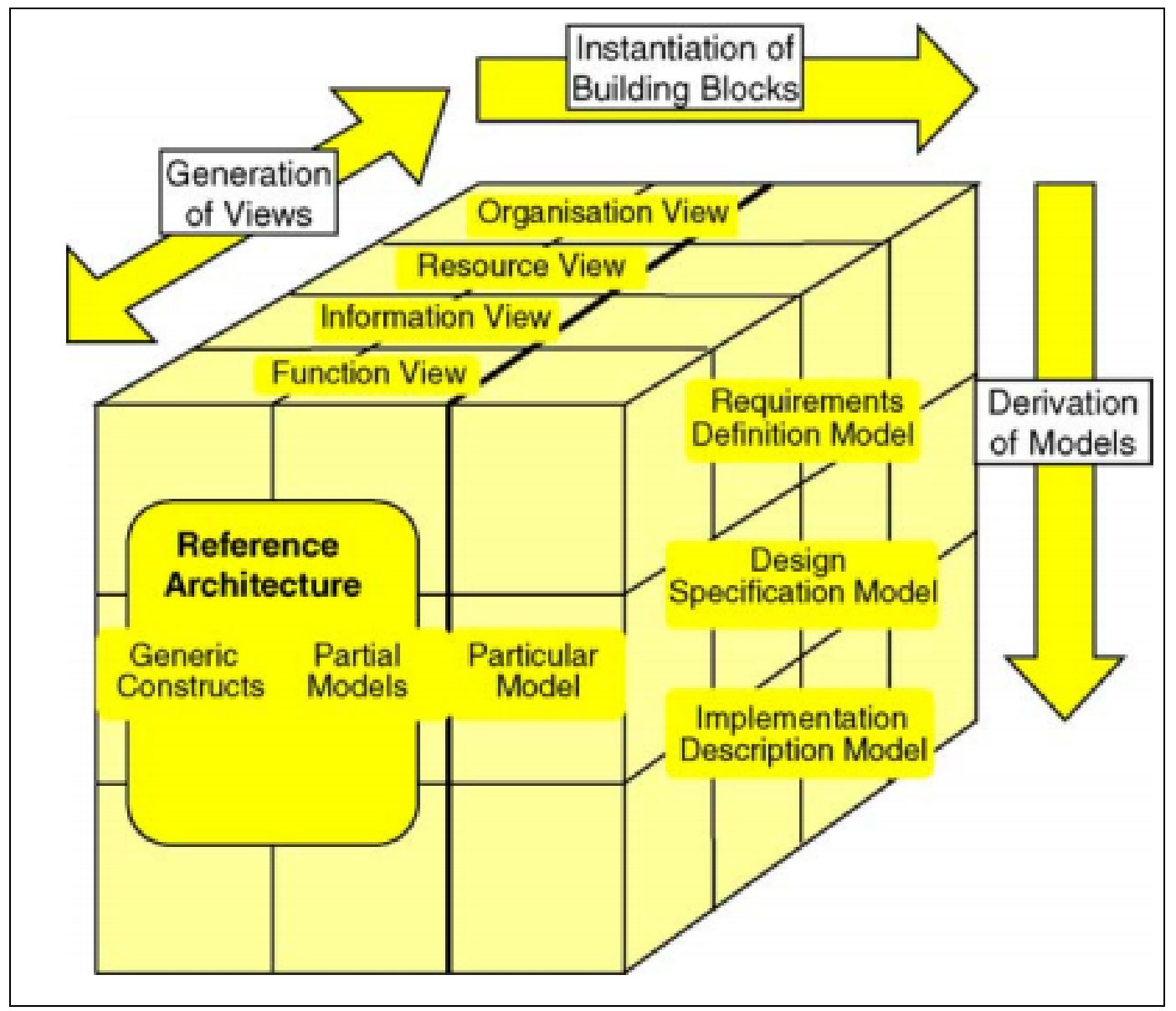

Figure 5: CIMOSA Archtecture Perspectives

Source: Anis, Spadoni and Vernadat. (2004)

In CIMOSA, modeling aspects are based on the organization's events. According to Weichhart, Stary and Vernadat (2017) the purpose of this modeling method is to describe the functions that are carried out in the company and its attributes at the level of detail desired by the user, thus differentiating themselves from the traditional business process modeling methods ; which are basically guided by the functional decomposition, that is, the division of the functions of the system modeled into sub functions.

\subsection{IDEF}


Like other architectures, IDEF presents diagrams and process flows in an organized way, allowing the identification of opportunities for improvement in the process.

Belavilacqua, Mazzuto and Paciarotti (2014) explain that the notation allows a complex analysis of the processes, considering their inputs, outputs, constraints and interactions. In this way, it is possible to structure a real-world logic model representing the behavior of the client and the way in which the client executes its actions in the system.

The IDEF modeling architecture is designed for business processes and sequences of a system, providing two perspectives, the process schema and the object schema. The concept of diagramming present in IDEF consists of two elementary aspects: a set of boxes (representatives of functions / activities); and arrows (representatives of driving data or objects).

The arrows are input, control and output (Input, Control, Output) mechanisms. However, such arrows do not lead to information flows, only data or objects to perform the functions and activities related to them. The structure of the IDEF architecture is given in figure 06 .

Sychenko, Mironov and Białon (2017) present a case study where IDEF is used in a domain of interest related to the repair of maintenance equipment of an electricity supply substation and define the modeling architecture as grouped methods for the representation of requirements necessary for the development of information systems, and can be used to develop tools, techniques and processes for industrial integration. 


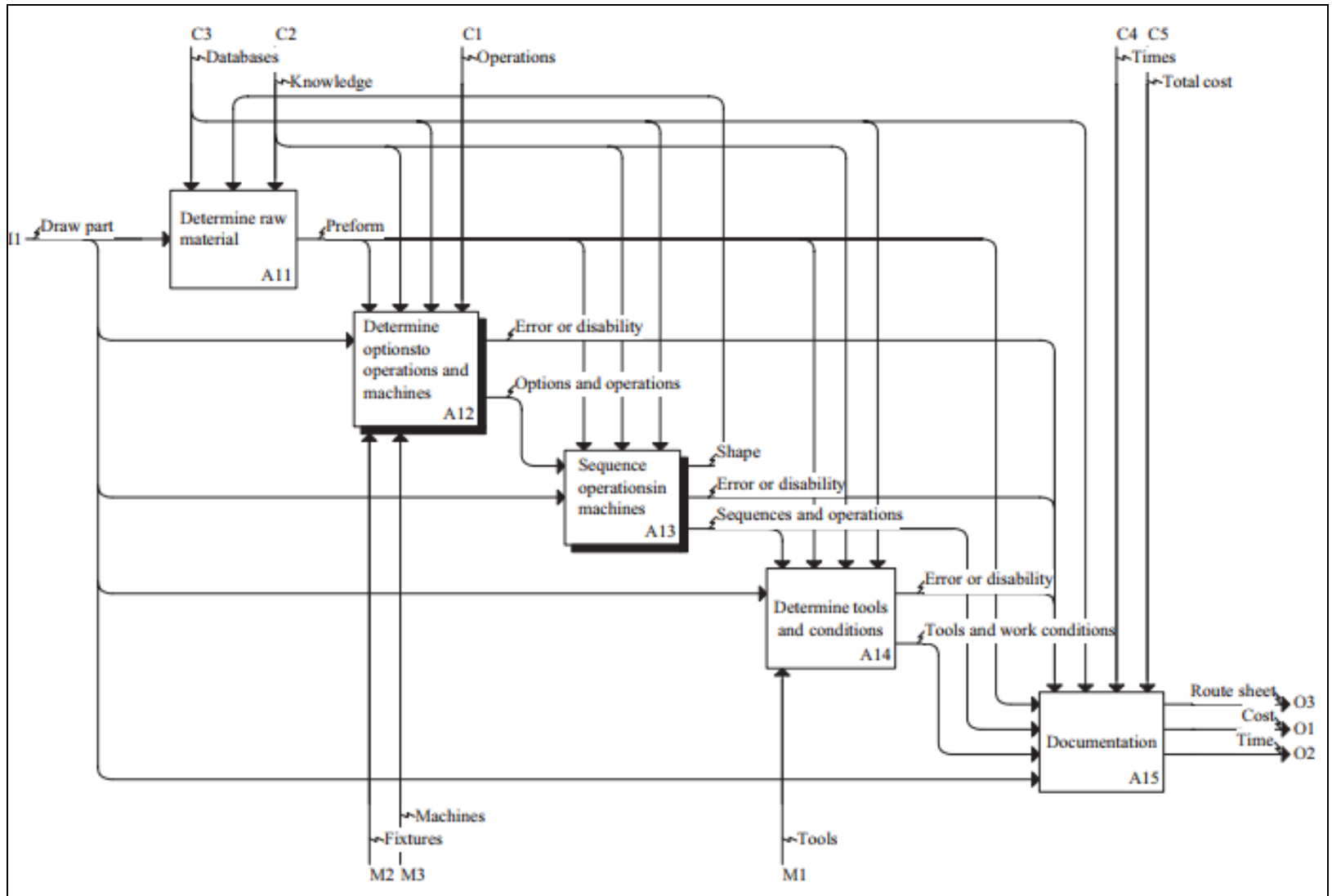

Figure 6: IDEF Architecture

Source: Nadezda, Foresti and Micheloni (2017)

The same authors emphasize in their case study the fact that IDEF allows the user to represent in a simplified way the main functions of input, output and mechanisms for the elaboration of activities and the controls that must be followed using the process diagram.

\subsection{Other modeling architectures}

The IEM framework, or integrated enterprise modeling architecture, uses an object-oriented approach and adapts it to the corporate description. An oriented division of all the elements of a company forms the core of the IEM in the generic classes of the object: "product", "resource" and "order".

Jin and Jäkel (2018) state that such classes can gradually receive complete and specified data (encouraging modeling), making it possible to show both the typical business line and the subclasses of company-specific products, orders and resources. Structures (e.g. lists of parts or organizational charts) can be shown as relational characteristics of classes. 
INDEPENDENT JOURNAL OF MANAGEMENT \& PRODUCTION (IJM\&P)

http://www.ijmp.jor.br

v. 10, n. 3, May - June 2019

ISSN: 2236-269X

DOI: 10.14807/ijmp.v10i3.886

As for the EKD modeling architecture, the authors Awadid and Nurcan (2016) define it as a methodology that aims to support both organizational change efforts and the development of information systems that effectively support the development of the organization.

Stirna and Persson (2009) complement the EKD architecture as a supplier in a systematic and controlled way to analyze, understand, develop and document an organization and its components using organizational modeling.

Briefly discussing GRAl's methodology (or method of engineering), we can see its presence in Business Process Modeling centered on the product manufacturing cycle, primarily involving the design part, emphasizing design, performance and functional aspects.

Lakhoua and Rahmouni (2011) explain the GRAI architecture as a systemic, collaborative and participatory approach that is adapted to the engineering design department modeling in order to support the structuring of both coordination decisions and design activity.

According to Bernus, Noran and Molina (2015), GERAM architecture, the last one addressed in the referential of this article, aims to generalize the contributions of several existing and emerging corporate modeling techniques, establishing the completeness and adequacy of these to form the basis for developing process improvement (since management can choose to combine the elements of more than one modeling technique and use them in combination).

According to Romero and Vernadat (2016), GERAM was developed to foster the use of all business reference architectures together (generalization). Therefore, it is assumed that they must have comparable characteristics and features.

Although there are other business process modeling architectures with relevant aspects for the development of the literature of the subject, it is believed to have chosen the most popular and diverse methodologies to compose this theoretical framework in order to promote a comprehensive and enriching discussion about the characteristics and process modeling elements to be addressed. 


\section{METHODOLOGICAL RESOURCES}

In the present paper, a qualitative research was carried out in which the principle of representativeness presented by Santos (2012) was obeyed, where a representative sample of relevant content from a consulted bibliographic universe was extracted rigorously. The quantitative approach also characterizes this work in the webibliomining review where the Web of Science database, an important source of scientific studies of international relevance, was used.

For the formulation of the theoretical framework of the paper, the most recent publications in the literature have been prioritized, focusing on works from the year 2016. Such chronological limit was broken for topics where no relevant publications were found or even where there were no publications of said subjects in the predetermined range. An example of this was some modeling architectures such as GERAM and IEM that have lost significant relevance in recent years.

Elementary quotations that offered a concise basis of understanding for the themes also had greater freedom outside the chronological limit because they represent information of high relevance and therefore enriching the body of the present article.

For the formulation of the systematic webibliomining revision, the CAPES journal platform was used through the consultation in the renowned Web of Science database. We did research using the following terms:

a) 'BPMN' AND 'Architecture'

b) 'UML' AND 'Architecture'

c) 'ARIS' AND 'Architecture'

(d) 'CIMOSA' AND 'Architecture'

e) 'IDEF' AND 'Architecture'

f) 'IEM' AND 'Architecture'

(g) 'EKD' AND 'Architecture'

h) 'GRAI' AND 'Architecture'

i) 'GERAM' AND 'Architecture' 
We used the search feature by topics, where we generated results that contained the terms searched in the title, keywords and abstract. The temporal filter was applied until 2017 aiming to collect only complete annual metrics. The results were also filtered to only detect articles from peer-reviewed journals. The results are displayed in section 4 .

\section{WEBIBLIOMINING ANALYSIS}

Analyzing the general aspects about the business process modeling architectures addressed in this article, one can promote the first classification in the proposed comparative view. Dividing these techniques into the classes of information systems: BPMN; UML; ARIS; IDEF; CIMOSA; EKD; and EMI. And in manufacturing support systems: GRAl; and GERAM.

However, all the reference architectures in process modeling considered in this article are treated in an equal degree of comparability for the proposed objective of developing the conceptual comparative vision seeking a better understanding of the performance of such architectures regarding organizational processes and organizational management environment .

Through the results of the analysis in the Web of Science database, it was promoted the acquisition of the webibliomining data components for the reference architectures in process modeling treated in this article.It is necessary to state that those results are a piece of collection of the most relevant and valuable content in the scientific literature.

A total of 369 articles were detected, with more than half of them (57\%) dealing with the UML architecture. The BPMN and CIMOSA architectures represented their popularity in the scientific literature with $12 \%$ of articles, both. The percentage relation of the articles referring to the architectures can be checked in figure 07. 


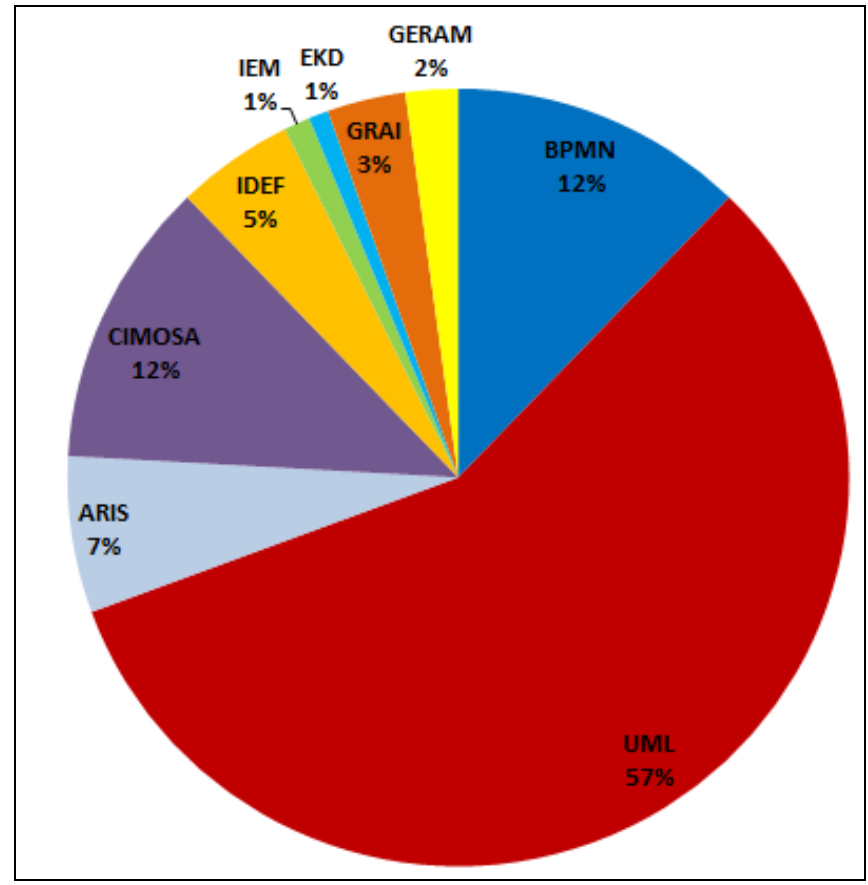

Figure 7: Percentage ratio of archival articles found in webibliomining

Table 01 shows the quantitative in descending order of such articles detected in webibliomining, followed by the predominant study area in which the studies of the modeling architecture in question are concentrated. The indicators of the authors and countries that published the most, as well as the percentage of articles in the English language make up the data analysis.

Table 1: Classification of the modeling techniques regarding the aspects

\begin{tabular}{|c|c|c|c|c|c|}
$\begin{array}{c}\text { Modeling } \\
\text { Architecture }\end{array}$ & $\begin{array}{c}\text { Paper } \\
\text { s Cited }\end{array}$ & Study Field & $\begin{array}{c}\text { Author with most } \\
\text { publications }\end{array}$ & $\begin{array}{c}\text { Country with } \\
\text { most } \\
\text { publication }\end{array}$ & $\begin{array}{c}\text { Paper in } \\
\text { English }\end{array}$ \\
\hline UML & 211 & Computer Science & Trujillo, J. & USA & $98,6 \%$ \\
\hline BPMN & 45 & Computer Science & $\begin{array}{c}\text { Chiotti, O. } \\
\text { Lorre, J. P. }\end{array}$ & Germany & $97,8 \%$ \\
\hline CIMOSA & 44 & Computer Science & West, A. & England & $100 \%$ \\
\hline ARIS & 24 & Computer Science & Scheer, A. W. & Germany & $95,8 \%$ \\
\hline IDEF & 18 & Engineering & $\begin{array}{c}\text { Venkateswaran, J. } \\
\text { Zakarian, A. }\end{array}$ & USA & $95 \%$ \\
\hline GRAI & 12 & Computer Science & Doumeingts, G. & France & $100 \%$ \\
\hline GERAM & 8 & Computer Science & Bernus, P. & Australia & $100 \%$ \\
\hline IEM & 4 & Engineering & $X$ & Germany & $100 \%$ \\
\hline EKD & 3 & Engineering & $X$ & USA & $100 \%$ \\
\hline & & Caption: & X Insufficient Data & \\
\hline
\end{tabular}


It is possible to conclude from the analysis of table 01, that the UML, BPMN and CIMOSA architectures can be clearly noticed as the three most numerous publications about the researched subject. Conversely, GRAI, GERAM, IEM and EKD display low numbers of detected articles.

The predominant area of study, in which the architectures are inserted, is that of Computer Science, with the exception of IDEF, IEM and EKD, which are predominantly inserted in the field of engineering. This fact can be explained by the fact that the approach of these architectures is more focused on the operational environment, while other architectures such as UML and CIMOSA are more focused on software engineering.

There is no surprise about the dominance of the English language in publications. However, the countries with the largest publication are diverse and varied, with Germany and USA being the most frequent representatives.

\subsection{Temporal aspects}

In the evolutionary aspect of the webibliomining analysis of the publications of the modeling architectures treated in this article, the three modeling architectures with the highest number of published articles were observed with more attention: BPMN, UML and CIMOSA. Their graphs relating to publication histories are given in figure 08, 09 and 10.

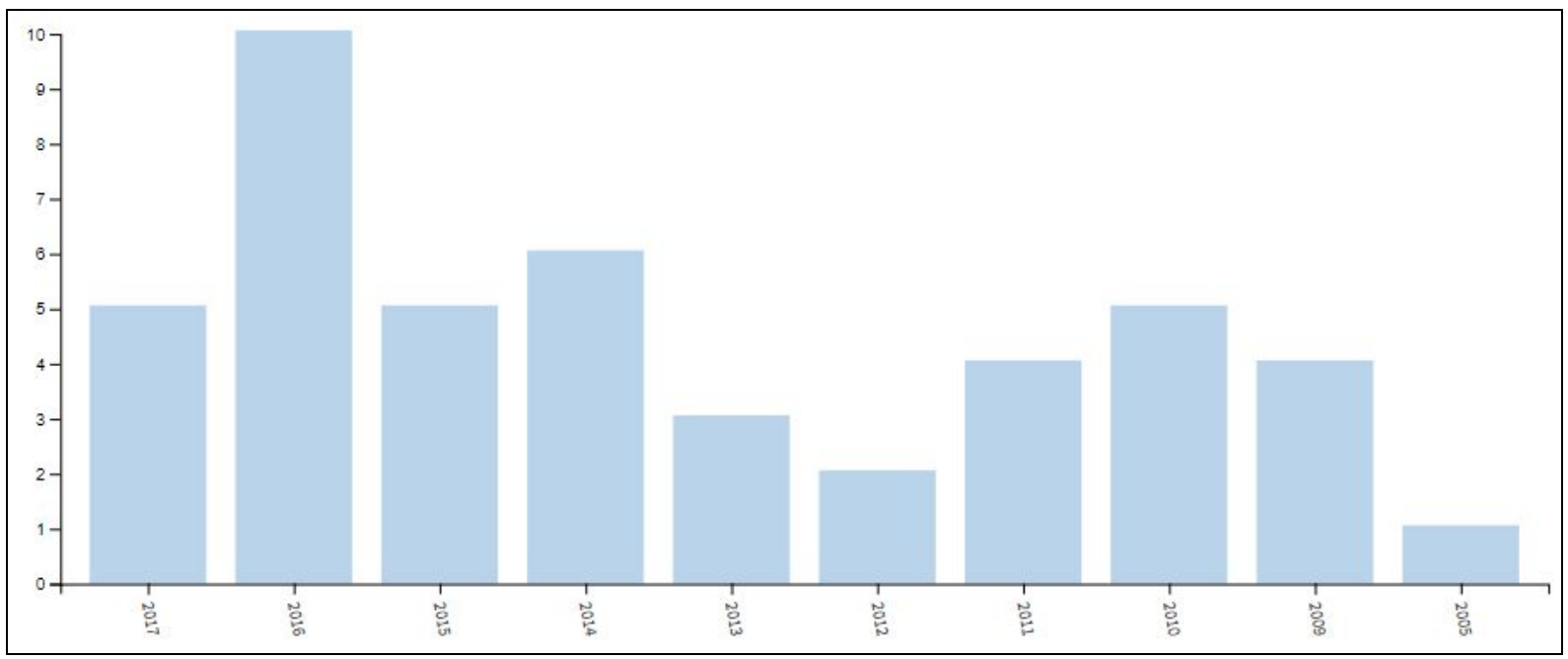

Figure 8: BPMN: Publications beetwen (2005 - 2017)

As can be seen in figure 08, publications related to the terms 'architecture' and 'BPMN' show a certain variability reaching its peak in 2016, with 10 published 
DOI: 10.14807/ijmp.v10i3.886

papers, and the lowest value in 2005 with only one article, find papers in the years 2008, 2007 and 2006.

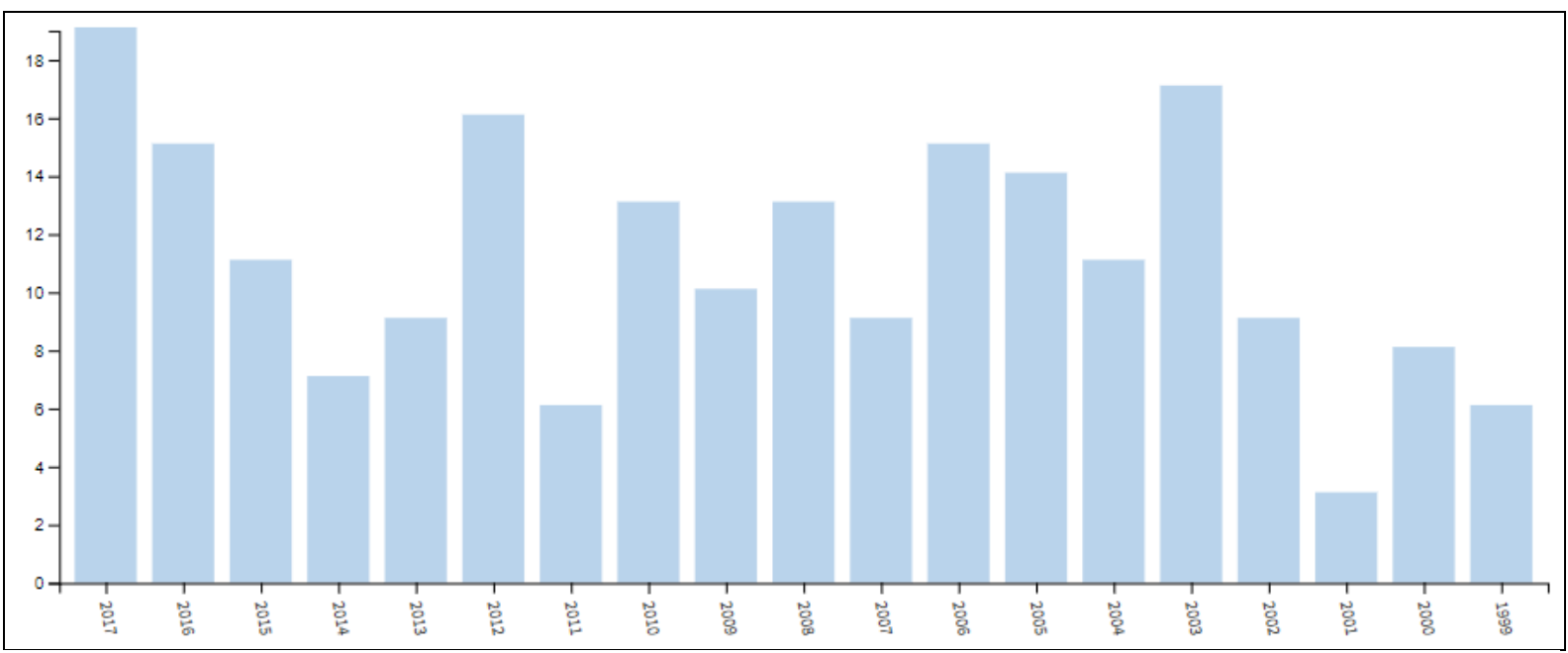

Figure 9: UML: Publications beetwen (1999 - 2017)

The publications on the terms 'architecture' and 'UML' (figure 09) show a larger quantitative with the first article dating from 1999. There is still a variable trend in the graph and its peak in 2017 with 19 published articles.

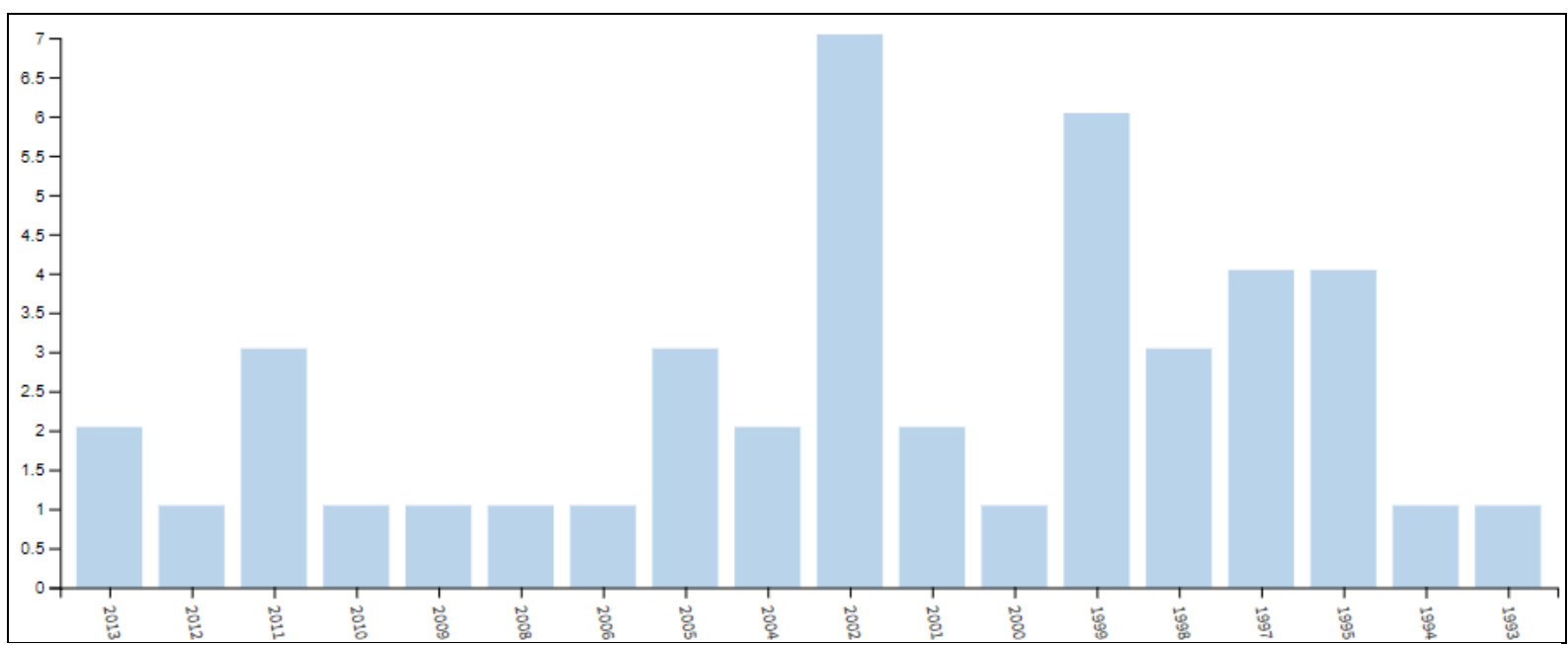

Figure 10: CIMOSA: Publications between (1993 - 2017)

The interpretation of the graph of figure 10 suggests some decadence of the themes related to the CIMOSA modeling architecture in the scientific literature because there are no articles published in the Web of Science database in the years 2014, 2015, 2016 and 2017. The peak of publications is in the year 2002, where 7 articles were published.

The architectures ARIS and IDEF, with 24 and 18 published articles, respectively, exhibit low number of publications per year and can be classified as 
INDEPENDENT JOURNAL OF MANAGEMENT \& PRODUCTION (IJM\&P)

http://www.ijmp.jor.br

v. 10, n. 3, May - June 2019

ISSN: 2236-269X

DOI: 10.14807/ijmp.v10i3.886

secondary architectures. Regarding IEM architectures; EKD; GRAI and GERAM, the publication gaps are significant during the period considered, suggesting a strong unpopularity in the scientific academic environment.

\subsection{Comparative analysis of modeling architectures}

In this topic, a systematic mapping study is promoted, relating the most relevant business process modeling techniques of the scientific literature. This study provided a comparative view of these architectures in relation to the aspects of the model, socio-technical characteristics and visualization and analysis elements of the model.

Regarding the comparative evaluation of the modeling architectures in the aspects of the model, the authors considered the following interpretation of the factors: Why (purpose of the model); What (model structuring); As (behavioral specification of the model); and Who (specification of stakeholders, actors of the process). In table 02, the evaluation in question can be observed.

Table 2: Classification of modeling architectures regarding aspects

\begin{tabular}{|c|c|c|c|c|}
\hline \multirow{2}{*}{ Modeling Architecture } & Why? & What $?$ & How? & Who? \\
\hline BPMN & $\tilde{N}$ & I & I & Ok \\
\hline UML & I & Ok & Ok & Ok \\
\hline ARIS & $\mathrm{I}$ & Ok & Ok & Ok \\
\hline CIMOSA & $\mathrm{I}$ & Ok & Ok & Ok \\
\hline IDEF & $\mathrm{I}$ & Ok & Ok & I \\
\hline IEM & $\tilde{N}$ & Ok & Ok & Ok \\
\hline EKD & Ok & I & Ok & Ok \\
\hline GRAI & $\tilde{N}$ & I & Ok & Ok \\
\hline GERAM & Ok & Ok & Ok & Ok \\
\hline \multicolumn{2}{|c|}{ Caption: Ok $=$ Adequate; I Insufficient; $\tilde{N}=$ Not Appropriate } \\
\hline
\end{tabular}

GERAM is perceived as the modeling architecture that fulfills all the requirements of the model according to the authors with excellence. However, as stated by Bernus, Noran and Molina (2015) and Romero \& Vernadat (2016), the creation of this reference architecture was an effort by developers of business process modeling to generalize contributions from other underlying architectures. Even the part of languages (and notation) UML and BPMN can be implemented in GERAM to represent systems.

As for the BPMN, one can see its incongruity in the question "Why", where the motivation to be promoting the modeling is not clearly structured to the participants 
DOI: 10.14807/ijmp.v10i3.886

of the process. This is corroborated by Van Der Aalst (2011), who says that the BPMN architecture focuses mainly on the information provided by process participants, through workshops or interviews, in order to trace the flow of the process. In this way, the flowchart is focused, and little attention is paid to the real motivation and modeling objectives (process improvement).

In tables 03 and 04, the analysis is enriched when considering the sociotechnical characteristics of the modeling architectures, in which the following factors are considered: Modularity (each unit of the model must encapsulate a specific objective, structure and behavior); Decomposition (referring to the capacity of the model to be broken down into parts); Responsiveness (ability to respond adequately to your environment); Autonomy (ability to react an external stimulus on its own); Intention (develop according to your goal); Adaptability (ability to adapt to a particular context or specific situation); Uncertainty (providing means for developing the model in an unknown context); Temporal (indefinite delay time between an action and its response).

Table 3: Classification of modeling architectures regarding socio-technical characteristics

\begin{tabular}{|c|c|c|c|c|}
\hline \multirow[b]{2}{*}{$\begin{array}{l}\text { Modeling } \\
\text { Architecture }\end{array}$} & \multicolumn{4}{|c|}{ Model Aspects } \\
\hline & 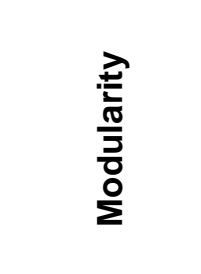 & 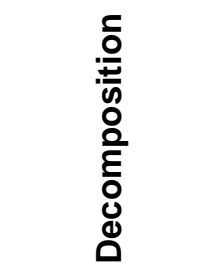 & 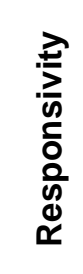 & 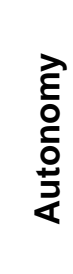 \\
\hline BPMN & Ok (How?) & Ok (How?) & Ok & 1 \\
\hline UML & $\mathrm{Ok}$ & Ok & $\tilde{N}$ & $\tilde{N}$ \\
\hline ARIS & Ok & $\mathrm{OK}$ & Ok & Ok \\
\hline CIMOSA & 1 & $\tilde{\tilde{N}}$ & $\tilde{N}$ & $\tilde{\tilde{N}}$ \\
\hline IDEF & OK & I & $\tilde{N}$ & $\tilde{N}$ \\
\hline IEM & $\tilde{\tilde{N}}$ & $\tilde{N}$ & $\tilde{N}$ & $\tilde{N}$ \\
\hline EKD & Ok & $\tilde{N}$ & $\tilde{N}$ & $\tilde{N}$ \\
\hline GRAI & 1 & $\tilde{N}$ & $\tilde{N}$ & $\tilde{N}$ \\
\hline GERAM & $\mathrm{I}$ & $\tilde{N}$ & $\tilde{N}$ & $\tilde{N}$ \\
\hline
\end{tabular}


INDEPENDENT JOURNAL OF MANAGEMENT \& PRODUCTION (IJM\&P)

http://www.ijmp.jor.br

v. 10, n. 3, May - June 2019

ISSN: 2236-269X

DOI: 10.14807/ijmp.v10i3.886

Table 4: Classification of modeling architectures regarding socio-technical characteristics (continuation)

\begin{tabular}{|c|c|c|c|c|}
\hline \multirow[b]{2}{*}{$\begin{array}{l}\text { Modeling } \\
\text { Architecture }\end{array}$} & \multicolumn{4}{|c|}{ Model Aspects } \\
\hline & 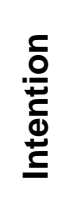 & 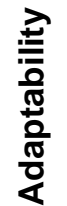 & 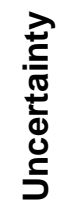 & 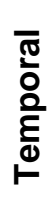 \\
\hline BPMN & $\tilde{\mathrm{N}}$ & $\tilde{\mathrm{N}}$ & $\tilde{\mathrm{N}}$ & $\tilde{\mathrm{N}}$ \\
\hline UML & $\tilde{\mathrm{N}}$ & $\tilde{N}$ & $\tilde{\mathrm{N}}$ & $\tilde{\mathrm{N}}$ \\
\hline ARIS & $\mathrm{I}$ & $\tilde{N}$ & $\tilde{N}$ & $\tilde{N}$ \\
\hline CIMOSA & $\mathrm{I}$ & $\tilde{\mathrm{N}}$ & $\overline{\tilde{N}}$ & $\tilde{\mathrm{N}}$ \\
\hline IDEF & I & $\tilde{N}$ & $\tilde{\mathrm{N}}$ & $\tilde{\mathrm{N}}$ \\
\hline IEM & $\tilde{\mathrm{N}}$ & $\tilde{N}$ & $\tilde{\mathrm{N}}$ & $\tilde{N}$ \\
\hline EKD & Ok & $\tilde{\mathrm{N}}$ & $\tilde{\mathrm{N}}$ & $\tilde{\mathrm{N}}$ \\
\hline GRAI & $\tilde{\mathrm{N}}$ & $\tilde{N}$ & $\tilde{\mathrm{N}}$ & $\tilde{\mathrm{N}}$ \\
\hline GERAM & Ok & $\tilde{N}$ & $\tilde{N}$ & $\tilde{N}$ \\
\hline
\end{tabular}

Once again one can notice the BPMN having its "How" aspect addressed in the characteristics of modularity and decomposition. UML diagramming notation, as defined by Larman (2002), shows a better degree of modularity and decomposition by being able to abstract (represent in a model) reality in different parts, which are its set of diagrams in the case. Similar to UML, the ARIS architecture is able to represent the system in different component parts of its model.

The GRAI reference architecture, which does not show significant popularity in the scientific literature, can be interpreted as simplistic and lagged when analyzed of its socio-technical characteristics compared to other more traditional modeling techniques.

According to Oertwig, Jochem and Knothe (2017), IEM does not offer sufficient adaptability to new industry requirements as a business modeling technique. These authors cite the example of materials management, information and cash flows, the pursuit of sustainable corporate development, which presents an additional challenge to decision makers.

In the last analysis, we have the comparison of the business process modeling architectures in the light of the aspects: Visualization (support for visualization of the model); Executability (machine interpretability, support for simulation / execution); Quantitative analysis; Qualitative Analysis. The comparative relation of these characteristics is given in table 05 . 
Table 05. Classification of modeling architectures regarding their visualization and analysis

\begin{tabular}{|c|c|c|c|c|}
\hline \multirow[b]{2}{*}{$\begin{array}{l}\text { Modeling } \\
\text { Architecture }\end{array}$} & \multicolumn{3}{|c|}{ Model Aspects } & \multirow[b]{2}{*}{ 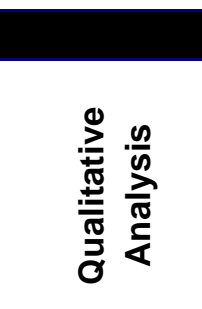 } \\
\hline & 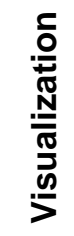 & 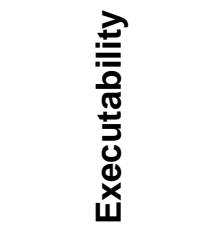 & 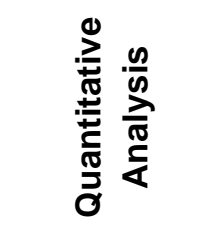 & \\
\hline BPMN & Ok & Ok (How?) & Ok (How?) & Ok (How?) \\
\hline UML & Ok & $\tilde{N}$ & $\tilde{\mathrm{N}}$ & $\tilde{\mathrm{N}}$ \\
\hline ARIS & Ok & Ok (How?) & $\tilde{\mathrm{N}}$ & Ok (How?) \\
\hline CIMOSA & Ok & $\tilde{\mathrm{N}}$ & $\tilde{\mathrm{N}}$ & $\tilde{N}$ \\
\hline IDEF & Ok & $\tilde{N}$ & $\tilde{\mathrm{N}}$ & $\tilde{N}$ \\
\hline IEM & $\mathrm{I}$ & $\tilde{N}$ & $\tilde{\mathrm{N}}$ & $\tilde{N}$ \\
\hline EKD & Ok & $\tilde{N}$ & $\tilde{\mathrm{N}}$ & $\tilde{\mathrm{N}}$ \\
\hline GRAI & Ok & $\tilde{N}$ & $\tilde{N}$ & $\tilde{\mathrm{N}}$ \\
\hline GERAM & Ok & $\tilde{\mathrm{N}}$ & $\tilde{\mathrm{N}}$ & $\tilde{\mathrm{N}}$ \\
\hline
\end{tabular}

Observing the executable aspects of modeling in relation to the UML architecture, Zur Muehlen and Recker (2013) affirm that in its diagrammatic part, there is not enough expressivity to describe executable computational functions, because its semantics is not so defined as necessary for this purpose. This fact becomes intuitive when one observes the purpose of the UML to be a notation of aid to the modeling. Differently from this concept one observes the exposed executability of the BPMN in relation to its unique module "How".

As for the qualitative and quantitative analyzes, we have the authors Yilmaz and Stirna (2015), who affirm that the syntax and semantics of EKD are not well defined formally and rigorously, being able to generate models ambiguous and difficult to interpret, mainly in systems, and it is not possible to verify the consistency and completeness of the model.

ARIS architecture, according to Ghatrei (2015), supports the analysis (qualitative) when exposing the sequencing of entities of the model; corroborating, therefore, with the results shown in table 05.

Finally, the control flow perspective (sequencing / ordering of activities) is often the basis of business process modeling architectures, as can be observed in BPMN, ARIS, UML (activity diagram). Other views, such as resource orientation (modeling focused on equipment, systems, organizational units, etc.) and the 
perspective of time and function (role / activities) are less explored in the scientific literature. This fact makes it possible to find expressive amounts of BPMN content and little material on EMI or EKD.

\section{CONCLUSION}

In this paper, it was reflected the reference architectures in business process modeling with the objective of elucidating a conceptual comparative view that could sketch, through comparative analysis provenient from relevant webibliomining research of the subject, an understanding of the function of such architectures organizational processes and their management environment.

Several reference architectures in process modeling have been cited and theoretically based (with the webiblioming resource), from the most important ones in the literature such as BPMN and UML to the least cited as IEM, GERAM and EKD, a fact that corroborates the methodological weight of the article and gives it scientific relevance.

It is concluded that the comparative analyzes shown foster the conceptual view of the state of the art of the literature about the architectures of business process modeling. Contributing, in this way, to researchers in future studies within the theme.

The purpose of the present paper is that research should be more aligned with the focus on the analysis of aspects, characteristics and functionalities of the models and their direct relation with the organizational processes.

Finally, as a limitation to the research, it is cited the use of only one database, Web of Science, which despite presenting dense and relevant content, may have left out of this paper articles that would be enhancing the subject.

\section{REFERENCES}

AMBLER, S. W. (2004) The object primer: Agile model-driven development with UML 2.0. Cambridge University Press.

ABDMOULEH, A.; SPADONI, M.; VERNADAT, F. (2004) Distributed client/server architecture for CIMOSA-based enterprise components. Computers in industry, v. 55, n. 3, p. 239-253.

AWADID, A.; NURCAN, S. (2016, June) Towards enhancing business process modeling formalisms of EKD with consistency consideration. In Research 
INDEPENDENT JOURNAL OF MANAGEMENT \& PRODUCTION (IJM\&P)

http://www.ijmp.jor.br

v. 10, n. 3, May - June 2019

ISSN: 2236-269X

DOI: 10.14807/ijmp.v10i3.886

Challenges in Information Science (RCIS), 2016 IEEE Tenth International Conference on, p. 1-12.

BARAT, S.; KULKARNI, V.; CLARK, T.; BARN, B. (2016) Enterprise modeling as a decision making aid: A systematic mapping study. In IFIP Working Conference on The Practice of Enterprise Modeling, p. 289-298, Springer, Cham.

BERNUS, P.; NORAN, O.; MOLINA, A. (2015) Enterprise architecture: Twenty years of the GERAM framework. Annual Reviews in Control, v. 39, p. 83-93.

BEVILACQUA, M.; MAZZUTO, G.; PACIAROTTI, C. (2014) A combined IDEFO and FMEA approach to healthcare management reengineering. International Journal of Procurement Management, v. 8, n. 1-2, p. 25-43.

BOOCH, G.; RUMBAUGH, J.; JACOBSON, I. (2006) UML: guia do usuário. Elsevier Brasil.

BRAGHETTO, K. R.; FERREIRA, J. E.; VINCENT, J. M. (2011, October)

Performance evaluation of business processes through a formal transformation to SAN. In European Performance Engineering Workshop, p. 42-56, Springer, Berlin, Heidelberg.

BUBENKO, J. A.; PERSSON, A.; STIRNA, J. (2001) User guide of the knowledge management approach using enterprise knowledge patterns. Stockholm (Sweden), Department of Computer and Systems Science, Royal Institute of Technology.

CHINOSI, M.; TROMBETTA, A. (2012) BPMN: An introduction to the standard. Computer Standards \& Interfaces, v. 34, n. 1, p. 124-134.

CONFORTI, R.; DUMAS, M.; GARCÍA-BAÑUELOS, L.; LA ROSA, M. (2016) BPMN miner: automated discovery of BPMN process models with hierarchical structure. Information Systems, v. 56, p. 284-303.

COSÍO-LEÓN, M. A.; OJEDA-CARREÑO, D.; NIETO-HIPÓLITO, J. I.; IBARRAHERNÁNDEZ, J. A. (2018) The use of standards in embedded devices to achieve end to end semantic interoperability on health systems. Computer Standards \& Interfaces, n. 57, p. 68-73.

FOWLER, M. (2014) UML Essencial: um breve guia para linguagem padrão. Bookman Editora.

GHATREI, S. (2015) ARIS Enterprise Architecture's Usage Reviews. Lecture Notes on Software Engineering, v. 3, n. 1, p. 57.

HAISJACKL, C.; SOFFER, P.; LIM, S. Y.; WEBER, B. (2018) How do humans inspect BPMN models: an exploratory study. Software \& Systems Modeling, v. 17, n. 2, p. 655-673.

JIN G.; JÄKEL F. W. (2018) Execution and evaluation of enterprise models in IEM/MO 2 GO based on Petri net. The International Journal of Advanced Manufacturing Technology, v. 96, n. 9-12, p. 4517-4537.

KARIM, S.; LIAWATIMENA, S.; TRISETYARSO, A.; ABBAS, B. S.; SUPARTA, W. (2017) Automating functional and structural software size measurement based on XML structure of UML sequence diagram. In Cybernetics and Computational Intelligence (CyberneticsCom), 2017 IEEE International Conference, p. 24-28.

LAKHOUA, M. N.; RAHMOUNI, M. (2011) Investigation of the methods of the enterprise modeling. African Journal of Business Management, v. 5, n. 16, p. 6845. 
INDEPENDENT JOURNAL OF MANAGEMENT \& PRODUCTION (IJM\&P)

http://www.ijmp.jor.br

v. 10, n. 3, May - June 2019

ISSN: 2236-269X

DOI: 10.14807/ijmp.v10i3.886

LARMAN, C. (2002) Utilizando UML e padrões. Bookman Editora.

LATIFFIANTI, E.; SISWANTO, N.; WIRATNO, S. E.; SAPUTRA, Y. A. (2017)

CIMOSA process classification for business process mapping in non-manufacturing firms: A case study. In AIP Conference Proceedings, v. 1902, n. 1, p. 020-040, AIP Publishing.

MENDLING, J.; RECKER, J.; REIJERS, H. A.; LEOPOLD, H. (2018) An Empirical Review of the Connection Between Model Viewer Characteristics and the Comprehension of Conceptual Process Models. Information Systems Frontiers, p. 1-25.

MOURA, P.; BORGES, R.; MOTA, A. (2003) Experimenting formal methods through UML. In Proceedings of the Brazilian Workshop on Formal Methods.

NADEZDA, Y.; FORESTI, G. L.; MICHELONI, C. (2017) An ADAS Design based on loT V2X Communications to Improve Safety.

PANAYIOTOU, N. A.; STAVROU, V. P.; GAYIALIS, S. P. (2017) The application of a business process modeling architecture in the supply chain of a manufacturing company: A case study. In Operational Research in Business and Economics, p. 1-16, Springer, Cham.

PESSINI, T.; SANTANDER, V. F. A.; DA SILVA, I. F.; DE ANDRADE, S. C.; SCHEMBERGER, E. E. (2017) BP2UC: De Processos de Negócios Modelados com BPMN Simplificado para Casos de Uso UML. Revista Eletrônica Científica Inovação e Tecnologia, v. 1, n. 15, p. 2.

ROMERO, D.; VERNADAT, F. (2016) Enterprise information systems state of the art: Past, present and future trends. Computers in Industry, n. 79, p. 3-13.

ROSA, M. L.; VAN DER AALST, W. M.; DUMAS, M.; MILANI, F. P. (2017) Business process variability modeling: A survey. ACM Computing Surveys (CSUR), v. 50, n. 1, p. 2.

SANTOS, F. M. D. (2012) Análise de conteúdo: a visão de Laurence Bardin.

ŠERIFI, V.; DAŠIĆ, P.; DAŠIĆ, J. (2008) Functional and information model of expert specialization using IDEF standard. Journal of Modelling and Optimization in the Machines Building Fields (MOCM), v. 14, n. 2, p. 268-279.

STIRNA, J.; PERSSON, A. (2009) Anti-patterns as a means of focusing on critical quality aspects in enterprise modeling. In Enterprise, Business-Process and Information Systems Modeling, p. 407-418, Springer, Berlin, Heidelberg.

SYCHENKO, V.; MIRONOV, D.; BIAŁOŃ, A. (2017) Structural-functional model of maintenance and repair of the traction substations equipment. TTS Technika Transportu Szynowego, 24.

TBAISHAT, D. (2017) Business process modelling using ARIS: process architecture. Library Management, v. 38, n. 2/3, p. 88-107.

TENIENTE, E.; WEIDLICH, M. (Eds.) (2018) Business Process Management Workshops: BPM 2017 International Workshops, Barcelona, Spain, September 1011, Revised Papers, v. 308, Springer.

VAN DER AALST, W. M. (2011) Process Discovery: An Introduction. In Process Mining, p. 125-156, Springer, Berlin, Heidelberg. 
VAN DER AALST, W. M.; ROSA, M.; SANTORO, F. M. (2016) Business process management. Business \& Information Systems Engineering, v. 58, n. 1, p. 1.

VERNADAT, F. B. (2003) Enterprise modelling and integration. In Enterprise Interand Intra-Organizational Integration, p. 25-33, Springer, Boston, MA.

WEICHHART, G.; STARY, C.; VERNADAT, F. (2017) Enterprise modelling for interoperable and knowledge-based enterprises. International Journal of Production Research, p. 1-23.

YAN H.; PIETER V. G.; MEMBER, IEEE, KAYMAK U.; IEEE, XUDONG L.; LEI J.; CHOO C.; HENDRIKUS H. M. K.; HUILONG D. (2018) Aligning event logs to tasktime matrix clinical pathways in BPMN for variance analysis. IEEE journal of biomedical and health informatics, v. 22, n. 2, p. 311-317.

YILMAZ, N.; STIRNA, J. (2015) Factors influencing productization of enterprise modeling: a qualitative inquiry into the scandinavian strand of methods and tools. In IFIP Working Conference on The Practice of Enterprise Modeling, p. 193-208, Springer, Cham.

YU, X.; GU, P.; LIU, X.; SUN, L.; QIAN, D.; GUO, Y. (2017) Modeling technology of virtual assembly system based on UML. In Electronics, Communication and Aerospace Technology (ICECA), 2017 International conference of IEEE, v. 2, p. 722-726.

ZUR MUEHLEN, M.; RECKER, J. (2013) How much language is enough? Theoretical and practical use of the business process modeling notation. In Seminal Contributions to Information Systems Engineering, p. 429-443, Springer, Berlin, Heidelberg. 